\title{
Global Brokers, Global Clients: A New Operational and Ethical Context
}

\author{
James W. Hutchin \\ Alba Advisors LLC, 1541 Farmers Lane, Glen Mills, PA 19342, USA. \\ E-mal: jhutchin@comcast.net
}

Brokers' reliance on ethical conduct as a critical element of their service package is not new. What has changed for a handful of brokerage firms is the extent to which, in response to client demand, they now operate on a "global basis", a phrase that has taken on multiple levels of meaning. An unintended consequence of this evolution has been the emergence of a series of challenges, some apparent and some not, to be managed in assuring "utmost good faith" as a consistent deliverable for all of a global broker's numerous constituents.

This paper will first analyze and then suggest some possible solutions for management of the very real risk issues arising out of the following factors for global brokers:

- the increasing complexities of an already highly fragmented industry "gone global,"

- a scale of operations with which there is little experience,

- "utmost good faith" as not just a goal of company culture, but also the objective of process management, and

- management of sometimes seemingly confused alignments, or as some would argue, conflicts of interest.

The Geneva Papers (2005) 30, 353-372. doi:10.1057/palgrave.gpp.2510036

Keywords: insurance broker; ethics; global insurance; contingency commissions; broker fees; placements

\section{Introduction}

Compliance is a cost of doing business. A consistent display of ethical behaviors can create a competitive advantage. An enduring reputation for integrity is often, but sadly not always, one of the elements that constitute a "leadership" position for a company in any given industry. The world of insurance operates in a unique context in which complex transactions are designed to put a precise price on uncertainty and are then delivered through a highly fragmented industry.

Broadly put, a broker's role (both broker as individual and as organization) is to first create and then administer for a client a risk solution that draws as needed on the resources and capabilities available both internally, and in the industry at large. Precision put to uncertainty can only happen through multiple-party transactions, and that can only occur when reliance on your counter-parties is not at issue. As a result, these maxims concerning compliance, ethics and integrity take on a particular validity in the field of insurance and reinsurance intermediation (brokerage); "utmost good 
faith" is not the quaint aspiration that some would label it, but rather an absolute operational requirement for functionality as a broker.

Although it is likely that he did not have brokers in mind when he first scribed it, Immanuel Kant's "categorical imperative", a moral principle by which to guide one's actions in life, should be burned into the psyches of brokers everywhere:

"I ought never to act except in such a way that I can also will that my maxim should become a universal law."1

The brevity is compelling, the call to action clear (this is after all an "imperative"), and no exceptions allowed. If this then is the ethical grounding from which intermediaries should operate, what then of the specifics, what in fact is actually owed the client? Numerous, and sometimes lengthy pieces have been written to detail the duties of a broker for his or her clients. Admirable for its succinctness, specificity, action "imperatives", and plain language, here is the "Statement of Ethics" from a prestigious Oklahoma City insurance intermediation firm, Midlands Management, that seems to capture it all nicely:

As employees of Midlands, its subsidiaries and affiliates we hereby recognize that the overall corporate ethics of Midlands is to be "beyond reproach" in all of our dealings with our clients, community, vendors and fellow employees. In keeping with this ethical mandate we agree to the following:

i We will act in the utmost good faith while dealing fairly and equitably with all parties involved in any transaction.

ii We will maintain confidentiality of all business transactions and information held in trust on behalf of our clients and fellow employees.

iii We will communicate with clients any potential conflict situations and at all times avoid situations whereby the interest of our clients and the interest of Midlands do not coincide.

iv We will continue to enhance our technical skills essential to the individual employee's position within the Midlands Group through continuing education programs fully supported by Midlands.

$\mathrm{v}$ We will strictly adhere to all statutory and regulatory requirements within our industry and keep fully informed of revisions regarding the same.

vi We will treat all parties with respect, fairness and honesty while pursuing an ideal of service that transcends self interest. ${ }^{2}$

A broker's reliance on ethical conduct as a critical element of their service package is not new. What has changed for a handful of brokerage firms is the extent to which in response to client demand they now operate on a "global basis", a phrase that has taken on multiple levels of meaning. An unintended consequence of this evolution has been the emergence of a series of challenges, some apparent and some not, to be managed in assuring "utmost good faith" as a consistent deliverable for all of a global broker's numerous constituents.

\footnotetext{
${ }^{1}$ Beauchamp and Bowie (1988, p. 37).

${ }^{2}$ The Midlands Management Companies (2004).
} 
This paper will first analyze and then suggest some possible solutions for management of the very real risk issues arising out of the following factors for global brokers:

- the increasing complexities of an already highly fragmented industry "gone global,"

- a scale of operations with which there is little experience,

- "utmost good faith" as not just a goal of company culture, but also the objective of process management, and

- management of sometimes seemingly confused alignments (or as some would argue, conflicts of interest).

\section{Globalization, fragmentation}

The risk business has long been dependent on a structure that houses the various specialties required to accomplish a transaction in different legal entities. This fact has been driven by the advantages of specialization, the many different types of buyers the industry serves, regulation, and as much as any other industry, custom and ingrained habit.

Underwriting a portfolio is very different from underwriting an account, and thus reinsurance tends to concentrate in those firms that have made a specialty of it and do not also write primary coverages. Intermediation, where no direct balance sheet risk is part and parcel of every transaction, allows for a more positive view of the likely outcome of a risk transaction. Professional risk managers, such as are found at large corporations, bring a learning curve advantage to the procurement of their needed insurances that the average homeowner can hardly begin to imagine.

The fragmentation of the industry allows for the accommodation of many differing needs arising from both the demand and supply side of the business equation. Captured graphically, the field (the "Commerce Chain") on which a broker operates appears as follows:
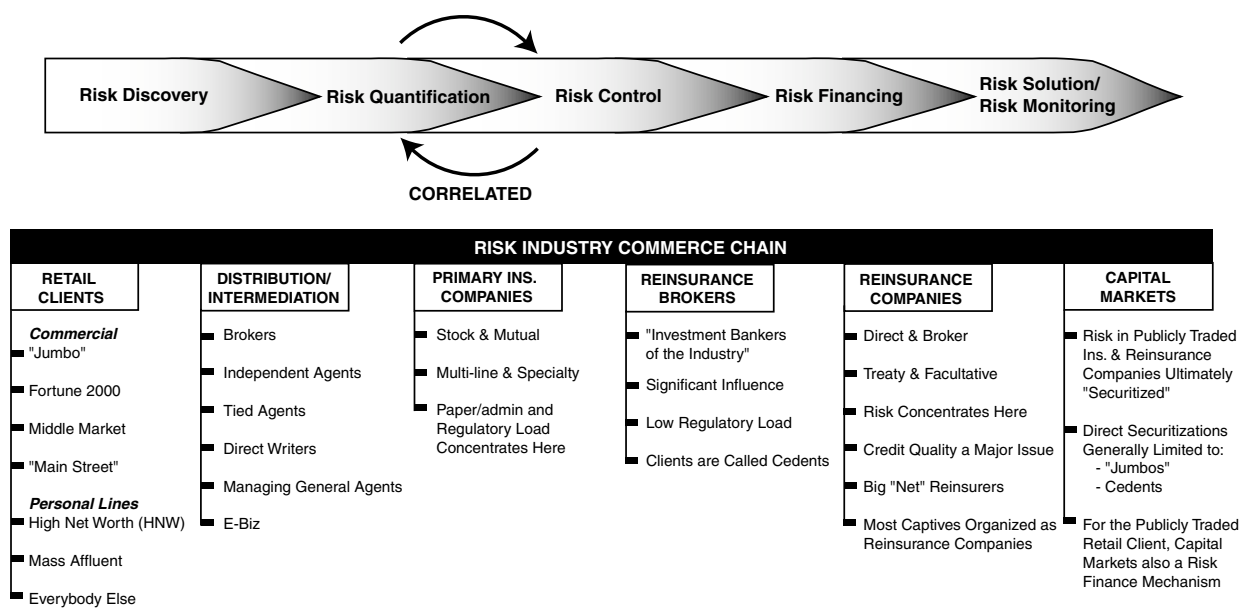
356

A "typical transaction" could be said to flow from left to right, with the path through this chain largely set at the moment you understand from which client segment the insurance purchase is emanating. For example, a "high street" company is most likely to be served by an independent agent in the U.S. and by a tied agent or direct writer in Continental Europe.

Global brokers must deal with a very different reality in servicing the needs of their global, or multinational clients. This difficulty arises from three critical issues that differentiate a global service package from that which would be provided for a domestic risk only, namely:

- the additional services required to adequately treat cross-border exposures,

- the very particular organizational and individual skill sets required to operate effectively on a global basis, and

- the growing propensity of large global clients to often view the broker as one of a series of providers in the commerce chain, and not necessarily as the "player" solely responsible for orchestrating the actions of all those in the industry called upon to put a risk solution in place.

These elements work in the aggregate to complicate the operational and ethical context in which a broker operates.

First, the very nature of a global account creates an exponential increase in the number of transactions, of both a financial and communication nature, which must be managed. Whereas a domestic account might require only two counter-parties (and their respective interests) for the broker to manage, that is the client and underwriter, a truly global account presents a radically different picture, and the numbers alone can be staggering. Presupposing a global client with operations in 25 different countries ( 26 clients, the risk manager at home office +25 local country managers), a worldwide carrier whose network is a part of the servicing package and the broker's own network of local servicing offices, the broker now has 76 parties to the transaction to manage.

Some harsh realities can set in. While one can certainly imagine successfully aligning and then communicating the joint interests that lead to action when three parties are involved, what are the odds of pulling that off with 76 parties to the transaction? Maybe the local carrier's office in country X does not want to write an all-risk form at a rate, part of a global transaction, which significantly undercuts the pricing strategy they have been trying to hold for domestic accounts. Maybe the in-country broker, not the beneficiary of the correlated business that goes with control of the global placement, is less than enthusiastic about working on a reduced commission and/or fee basis. As the number of parties to the transaction increases, so too does the probability of divergent interests, and with that the potential for someone motivated by selfinterest to act in a less than ethical fashion as they attempt to "game the system" to the outcome they seek.

The multiplicity of clients in a single global engagement can also put the broker in the position of having to make a Faustian choice. How, as the local broker, do you respond to the CEO of a major, in-county subsidiary, when asked not to report a potential claims situation to your control office, and thus the client's home office, out of concern for the negative impression it might make (“... don't worry, we can handle 
it here...")? Given the many interests served, global brokerage firms have staff that are often faced with a choice of conflict or collusion; they should not be envied.

As one crosses borders with an insurance transaction and thus operates concurrently in a number of regulatory environments, ethical challenges for brokers can arise in managing what may be compliance issues operating at cross-purposes. For the global client with a subsidiary in a locale where a restrictive market precludes placement of a local policy to address a given risk, do you as the broker offer a readily available non-admitted alternative (i.e., a policy written outside of the country where the risk is located) knowing that the option may not be legal in the country where the risk is located? If you do so, what risk do you create for your client, both at the home office level and abroad, as well as your own in-country office?

One of the more striking and admirable elements in the Midlands Statement of Ethics is the extent to which continuous learning is treated as an ethical imperative. This learning imperative takes on a whole new context for the brokerage firm operating globally, as on its success hinges the possibility of staff being able to represent accurately, and thus ethically, to a client and/or prospect the value proposition of the firm being offered. Global clients are making three assessments in the purchase of global risk services:

- the organization from which they are procuring services,

- the individual that will lead the engagement, and

- the "Great Unseen", that is, the organization(s) and individuals outside of their home country who will form a critical component of the service delivery system (such as the broker's and underwriter's global networks).

Meeting these criteria is difficult in the best of situations; doing so ethically is a function of absolute veracity in representations about what the broker can and cannot deliver on a global basis. Representing ethically what you can do on a global account is a function of understanding global business. The risk business firm (broker and/or underwriter) with staff responsible for a global engagement who have never worked outside of their home countries, conducted business in a second language, or bothered to learn the metric system, is unlikely to bring to the table a vast array of both tangible and intangible skills absolutely essential in conducting business across borders and cultures.

Referring to the risk business commerce chain shared earlier, an ethical complication unique to the global brokers is the fact that for the jumbo clients of this world, there is (unlike other client segments) no single and recurring "path" that they pursue in assembling their risk solutions. Some utilize a single broker as "point person" for all that happens with their risk programme, many utilize a panel of brokers charged with handling a specified line(s) of coverage, and still others make no use of brokers at all. The vast majority have established their own captive insurance company subsidiaries and are in that sense themselves direct participants in the industry from which they are purchasing risk services and financing. As would be expected from the market segment sometimes described as "trophy clients", their risk managers are highly professional, demanding, and not afraid to use their buying clout 
in negotiating best terms. This combination can change the nature of the client relationship.

Performance pressure on all parties is greatly increased, and this in turn skews the odds of an ethical lapse in the management of the account. A small, privately held firm is not going to be happy about a significant, unbudgeted increase in premium spend or an uncovered claim. On the other hand, a publicly traded firm, when faced with the reality of quarterly earnings reports and beady-eyed analysts, will sometimes find the pressures focused on staff to hit "targets" productive of less than ethical decisions as regards any one of the myriad data-sharing items that constitute an insurance transaction. The broker involved runs the risk of becoming a witting, or sometimes unwitting colluder. And, as publicly traded entities themselves, the largest brokers are faced with these same issues internally; there may be as many ways to "manage" the timing of revenue recognition as there are artful brokers. Constant vigilance is a requirement of going to scale as a broker.

And in what is an odd paradox of the market, there may actually be less contractual oversight from the industry built into the "jumbo" transactions than there is in more conventional placements. For example (and always a function of market conditions), as a small insured looking at buying property coverage, I am typically faced with buying a highly regulated form, reporting full values, and then putting my veracity to the test in the event of a claim via a "proportional" (for those in the U.S., a "coinsurance") clause.

A Fortune 500 firm, on the other hand, would look to, and in a soft market expect to achieve a manuscript form, and wording to the effect that "...values are reported for premium computation purposes only and shall not limit the coverages provided by this policy...." "Errors \& Omissions" clauses will provide a bit more relief in the advent of "mistakes" in managing the data flow, and in what strikes many as a near absurdity, when all else fails, even the buyer of a manuscript form can claim in common law countries that as a "contract of adhesion" (one party signatory, the issuing insurance company) any ambiguity should be interpreted in the insured's favor.

Few professional risk managers at global firms feel overly bound by convention, and quite rightly so; their duty to their firm is clear, and they hold the position they do because of the knowledge they have of the industry. As a result, and often to their employer's benefit, they feel quite comfortable in communicating directly with others in the chain of commerce, even when those parties are part and parcel of an insurance solution structured and maintained by a contracted broker. In the absence of meticulous coordination with the broker, the risk of miscommunication is high, and the consequences only truly known when a problem emerges.

So, add it all up; a multiplicity of sometimes conflicting interests represented in one client engagement, numerous outside parties to the transaction, a shifting and varied regulatory environment, challenging competency requirements for staff, sometimes confused or incomplete communication, and all of it operating in a system under extreme pressure. Global brokers may not be paid enough, and there are better ways to calculate their compensation than the legacy commission and contingency systems employed (more on this later). 


\section{Managing scale}

"Madness is rare in individuals - but in groups, parties, nations, and ages it is the rule.",3

Any organization has the potential of being only as ethical as its least ethical member. And, as your scale increases, the correlated increase in your "power" produces both a broader range of ethical lapses with which staff might be tempted, as well as a higher standard to which all your constituencies (regulators, shareholders, employees, clients) will hold you. Witness some of the Citigroup experiences in 2004.

Using its scale as a competitive advantage and the speed facilitated by electronic markets, Citigroup is alleged to have executed a series of transactions that flooded the market with the sale of $\$ 13.5$ billion of European Government bonds in a two-minute period. Thirty minutes later, it bought back $\$ 4.94$ billion of the same bonds in a now depressed market that had been overwhelmed with supply (of Citigroup's making), and netted a profit estimated at $\$ 18.52$ million. As the furor over the transaction broke, along with investigations by several governmental agencies, Tom Maheras, Citigroup's head of global capital markets, released an e-mail to all staff, in which among many other things, he said, "We did not meet our standards in this instance, and as a result, we regret having executed this transaction..." The reverberations for Citigroup continue. Owing largely to concerns about the methods employed in the sale of structured bond transactions, its private banking operations in Japan have been shut down by regulators. ${ }^{4}$

As one of a nearly endless menu of ethical "errors" available to those in banking, clearly this is one that would not have been available to a small, regional bank. The culture that arises in market-dominating firms may also lend itself, perhaps unintentionally, to the inappropriate wielding of power that they in fact set out to create by achieving massive, global scale; gather enough "master of the universe" personalities in one corporate house, and bad things happening may be nearly inevitable. Skeptics would ask whether the "regret" (such a better word than "sorry", which never appears in memos to staff) felt at Citigroup arises from the ethical transgression itself, or from having been caught. Had the market and regulators not spotted this "innovative transaction" (as it was described by Mr. Maheras in his memo to staff), would it have produced admonitions for the staff involved, or a bonus?

Cynics would pose a far tougher question: Can firms in the financial services industry reach a scale such that they are no longer structurally capable of operating as an ethical organization (this is not to say that they are not populated by many ethical people)? Those arguing for an affirmative response would cite:

- A required span of control and transactions not realistically achievable.

- Power that comes with scale, the exercise of which - and sometimes experimentation (e.g., "innovative transaction") - is bound to produce correlated ethical lapses.

\footnotetext{
${ }^{3}$ Nietzsche (1966, p. 90).

${ }^{4}$ Simensen and Ibison (2004); Batchelor, Skorecki and Simensen (2004); Wighton (2004).
} 
- The ability, some would say tendency, of truly global firms to set their ethical boundaries not by a proscriptive establishment of standards internally, but rather by a reactive (to constituencies, primarily regulators) recognition of the "borders" the firm seeks to continuously test and expand.

- The difficulties, in the light of the preceding, in maintaining a consistent corporate culture that continuously promotes and rewards ethical behavior by staff.

Others, just as vociferously, would argue that through tightly defined process management, zero-tolerance of transgressions, strong company culture, and "constant vigilance", even very large firms are capable of achieving organizational integrity. Additionally, scale can actually allow a company to do more good when its mind is set on it. Feeling the pain of large firms in their struggle to manage the "can't win for trying" syndrome associated with managing ethical perceptions of their firms, Malcolm Forbes once cited the following ditty:

You're gouging on your prices if you charge more than the rest.

But it's unfair competition if you think you can charge less.

A second point that we would make to help avoid confusion:

Don't try to charge the same amount - that would be collusion!

You must compete. But not too much, for if you do, you see,

then the market would be yours - and that's monopoly!

- R. W. Grant, Tom Smith and His Incredible Bread Machine ${ }^{5}$

There are many reasons for creating scale in an organization, pricing "power" clearly being just one. Few would question that global insurance and risk services buyers have enjoyed numerous benefits from being able to deal with those brokerage firms that have with their size created a global reach, an unprecedented menu of risk services from which to choose, and the access to intellectual capital that comes from housing that much talent in one company.

Of interest is the apparent fact that as a result of having to pay for those resources, "economy of scale" may not be a concept that plays well in the world of brokerage. Although it could only be considered anecdotal in nature, it is striking that in the special edition (July 2004) that it issues each year, Business Insurance's list of the world's ten largest brokers did not include one from its list of the world's 10 most efficient brokers (as measured by the industry standard of revenue per employee). ${ }^{6}$

As if these factors were not challenging enough, the relatively small number of insurance brokers to have truly achieved global scale are faced with a unique set of circumstances in their efforts to manage the ethical content of their firms:

- There is little learning curve advantage in the industry itself in managing brokerage operations on the scale now occurring, and in a business model reliant on process rather than craftsmen.

\footnotetext{
5 Tobias (2004).

${ }^{6}$ Business Insurance (2004, p. 16).
} 
- As a result, some ethical boundaries are fluid and still evolving. Few clients would question the use of newly created "market muscle" to achieve favorable terms on a desired placement, but what if I use that same buying clout to reward my shareholders, as they too justly expect? And what of underwriters, are they "partners", or simply a counter-party that should hold no deluded notions of a broker not seeking to achieve all advantage "legitimately" (whatever that means) possible.

- Insurance transactions are also unlike most others in the financial services world:

- They can have duration measured in decades.

- They are concluded with parties with whom the broker will have to conclude many other transactions to be successful in his/her career as a broker.

- They are not all truly tested as that only happens for those policies where a claim occurs; insurance is transaction management by exception.

- They can rarely be said to be fully concluded, "done and dusted"; every underwriter has a defence of "false inducement" in not paying a claim (which is why J.P. Morgan will no longer accept surety bonds as collateral for any transaction).

- The "market" is essentially the aggregation of the personal relationships with underwriters of the transactional brokers in the firm.

- The two parties to the transaction are dealing with different types of risk, the client with pure risk, and the underwriter with business risk.

- Much of what passes for process management in the world of brokerage is the product of folkways in a very traditional industry codified as procedures, rather than the product of sound, ground up analysis.

Finally, there is the "elephant in the room", the issue understood by all yet rarely acknowledged. The balance sheets of the global brokers attract unwanted attention in that many buyers view the scale of these firms as offering a decided advantage because in the event of an unpaid claim, their broker will have the wherewithal to become an insurer of last resort via the mechanism of an errors and omissions lawsuit. Global brokers have much to consider.

Managing the ethical component in a business enterprise is an issue to be considered regardless of scale, and how best to accomplish that has long been an important component of business thought.

An early piece of technology to facilitate the process, to allow for the Ronald Reagan adage of "...trust and verify..." was the partners' desk built and sold primarily by 18 th and 19th century English furniture makers. Resembling two normal desks that had been joined across their backs, it created a single piece of furniture that would place the two partners in a firm (the simplest form of business organization) face to face over the course of their working days. This was not done just to provide more of the sheer joy of your partner's company, but also to allow for a real-time monitoring of the work he was conducting, of compliance, of ethics monitoring writ small. The concept still holds; the methodologies are changing.

\section{"Utmost good faith", an utmost deliverable for process management}

Nineteenth century furniture was generally the product of a craftsman, a single individual knowledgeable in all the varied skills required to produce a partners' desk, 
or another item ordered by the customer. From the seasoning of the wood, to the planing, the cutting, the assembly to a proprietary design, the entire process was the work of one individual. Purchase a piece of manufactured furniture today and you are clearly the recipient of a bit of industrial "output" and not of the singular work of an artisan.

Global brokers are in the midst of evolving from a craft model for their discipline and are moving rapidly to a process management, at times almost industrial model for the delivery of their value proposition. Shaped by the growing complexity of risk, customer demand, and their own economic realities, three distinct stages have marked the evolution of the brokerage business, with true global brokers being the most recent iteration to emerge:

(1) Broker as craftsman: The broker performs all the requirements arising from a client engagement and is responsible for bringing in the business, assessing the risks the client seeks an insurance solution for, placing coverage, and then administering the programme (including advocacy in the event of claims activity). This is the model under which nearly every brokerage firm began and can be found today at only the very smallest of operations.

(2) Broker craftsmen in a "guild" (company) supported by a team: This model places at the broker's disposal a team of specialist and support staff who can be utilized to form ad hoc teams to meet particular customer requirements. The broker is likely now to carry the title of "client executive" but still has what is essentially a clientto-market (insurance companies) span of control in the management of the account, and notwithstanding every effort of the firm for which he or she works, views it as a proprietary asset.

(3) Brokerage services as a process management deliverable: This approach, still very much in its early stages, seeks to achieve the advantages of specialization and economies of scale for both the client and the brokerage firm. A "client executive" position still exists, but the role is now very different; disaggregation of the delivery model into a very large menu of possible components requires a designated role for the assembly and oversight of client-specific service packages. There is no longer one individual a client could point to and say, "...that is my broker", in the traditional meaning of the word.

The transition from stage 1 to 2 has been for most brokerages a naturally occurring process, fuelled typically by growth (a pleasant sort of business problem) and supported from within. It provides a better platform for the essentially entrepreneurial personalities attracted to brokerage to practise their craft, and could significantly improve the breadth and quality of service delivered to the client. Ethics management in the craftsmen supported by the teams model of brokerage is typically marked by the following:

- A heavy reliance on employee selection processes; an at times "club" style of choosing and recruiting staff, with a heavy reliance on prior experience with the individuals asked to join the firm.

- Culture, culture, culture as the most effective means of transmitting corporate expectations with respect to ethical standards. Although your employee count may 
be relatively high, the number of craftsmen/brokers who actually control the book of business is low, so a culture-driven approach can deliver genuine ethical efficacy in a firm with a lean organizational structure.

- A continuous broadcasting to the firm of the financial risk posed by ethical lapses in the form of resulting errors and omissions claims activities. Both the shareholding and compensation structures of stage 1 and 2 brokerage firms tend to align the interests of the firm and the employees quite tightly.

The handful of brokerage firms now entering the brave new world of process management as the mechanism for delivering value are faced with the challenge of operations and ethics management on a scale with which there is no learning curve advantage. In fact, carrying to the new model of brokerage procedures and methodologies that worked for the "craftsmen" of old can often be more problematic than helpful.

The challenge of scale for the global brokers is not just a function of the business flowing through their firms but, from the perspective of ethics management - and perhaps more importantly - it is the volume of communication(s) and "hand-offs" that now comprise the day-to-day work on an account. In a craft model of brokerage, communication flow has a single control point, that being the "controlling" broker who is either the recipient (sometimes via a copy) and/or transmitter of every communication that touches the client.

With the vast array of services a global brokerage can now offer its clients and the resulting flow of communications that fact causes, volume alone precludes the client executive from being part and parcel of every client interaction. Further, in those brokerages that have separated client servicing and market placement functions, as most of the "globals" now have, the client executive may by process design be the recipient only of "outputs" from another unit in his or her organization, and not necessarily an active participant or shaper of outcomes in what may well be the critical component of the service package.

Span of management control is not the only issue that arises. In a craft model of brokerage, odds are high that the individual rising to the position of client executive has either direct experience with and/or a working knowledge of each of the more limited (compared to global brokers) service offerings of his or her firm. This translates into a grounding in each of the practices for which they provide an ethical "control point", an understanding of how systems can be gamed; in short, the "nose" (judgment) to detect rapidly when a given course of action runs the risk of an ethical lapse.

In a global brokerage, with a massive menu of services available to clients, similar expectations of your client executives could well border on the unreasonable; in a very real sense, for those that control an account at any financial services giant, "span of competency" may be a more challenging issue than span of control. As a result, for the global brokerages, particularly those seeking to create true, comprehensive risk services firms, less reliance can be placed on ethical oversight by way of the cadre of client executives and the culture you hope to have imbued them with. And, apart from the often-difficult issue of "who watches the watchers", there is the fact that some of the most productive staff may not fully buy into a process management approach to begin with. 
Nearly every team to manage a large brokerage firm has struggled with the question of how best to "institutionalize" an account, that is, embed the relationship value that maintains the engagement in the brokerage firm itself, rather than the individual (broker/client executive) who produced the account. Accounts that are not so managed are subject to walking out the door the day that the producing broker controlling the engagement finds greener fields elsewhere, a skill well honed by many over the years. Particularly for the sometimes "grizzled" veterans that have made a career of "controlling" (or simply believing that they do) what they perceive to be a proprietary portfolio of "their" business, their management team's movement to carefully structured processes can be simply interpreted as a disenfranchisement of their personal operational and economic value. So, they leave, typically attracted to a smaller firm offering the allure of a craft model.

It is all about change, four unintended consequences of which are as follows:

- Conflict

- Confusion

- Created incompetency

- A sense of loss

Regardless of the industry, most firms are very good at dealing with the structural and procedural change management associated with process redesign and/or new business rules implementation, yet they seldom give adequate attention to the human element. As the inevitable fallout develops, many find themselves echoing the lament of Henry Ford when he first implemented an assembly line approach to manufacturing automobiles, "Why is it that when all I want is a pair of hands, I get a whole human being?",

The whole human being, particularly when coping with the by-products of change enumerated above, is the source of the ethical transgressions that could bring down even the largest of firms. Few would have thought Arthur Andersen subject to as rapid a death spiral as it experienced, but in a business where your key operational asset is the veracity of the representations that you make, once that was lost, Andersen had in the eyes of clients worldwide lost its raison d'etre. Brokerage is little different.

Errors and omission claims ("E\&O") are the transformers by which a brokerage suffers the economic havoc resulting from a failure in processes or ethics; the loss in reputation, in brand equity, that can accompany an E\&O claim might best be thought of as "collateral damage", the potential severity of which the Arthur Andersen meltdown illustrated for all. Nearly every E\&O claim can be traced to one of six root causes:

- Failure to follow procedures

- Inadequate and/or improper documentation

- Insufficient knowledge of the client's entire account

- Complex programmes, and a failure to educate the client

\footnotetext{
${ }^{7}$ Pollard (2004)
} 
- A change in your counter-party at either the client or underwriter level

- Attempts to fix a "problem" when detected without calling in help from others in the firm.

In a process management model of brokerage, each and every one of the staff members responsible for the discrete component of the service package they provide must be sensitive to and continuously guarding against loss for the firm arising from the preceding points. They must be inoculated against the ethical lapses and process failures that could lead to an E\&O loss. If "culture, culture, culture" is the appropriate approach for guarding one's ethical context in a craft brokerage, for the global firms it is now clearly "training, training, training."

Men's Health magazine, not among the more scholastic of journals, recently commissioned a scientific survey conducted by the Opinion Research Company, the results of which would can only be termed "disturbing":

- Eighteen per cent of men think that it is acceptable to misrepresent corporate finances in the manner of an Enron,

- Twenty per cent believe that it would be "OK" to divulge company secrets in a job interview with a competitor,

- Twenty-nine per cent would follow a supervisor's instructions to do something unethical, and

- A full 50 per cent see no ethical conflict in passing along a stock tip obtained with proprietary, "insider" knowledge. ${ }^{8}$

Particularly for the global firms creating a new model of brokerage, a "build your own" approach with young staff has much appeal. Starting with an "uncarved block," it is easier to slot staff into a new process model, and have far fewer preconceived/learned notions to deal with. But there is a dangerous bit of baggage that many new staff arrive with today, and that is a sometimes inadequate grounding in the ethical context, which constitutes an absolute requirement for operational success as a broker.

A process model of brokerage also makes it much more difficult for new staff to truly understand the mission of the firm and the totality of its value proposition. In a craft model of brokerage, odds are high that a year into my career I am handling my own modest portfolio of clients; they are likely to be small, and I am certain to be given much supervision. However, the critical condition created from a learning perspective is that there is perfect symmetry between what I do on a day-to-day basis and the mission of my firm. A year into my career at a process management model of brokerage - and if not the recipient of very carefully structured training - I may now be among the world's finest at reconciling workers compensation retros, but be woefully ignorant about all the interconnecting elements that go into the construction of a broker's total service package.

${ }^{8}$ Berreby (2004). “Are You a Man of Character?” Men's Health. October 2004, pp. 192-199. 


\section{Managing alignments of interest ${ }^{9}$}

Any intermediary, in any field, will be faced continuously with the potential of either intentionally or unintentionally entering into a "conflict of interest", well defined on the useful website www.ethics.org as follows:

A person has a conflict of interest when the person is in a position of trust which requires her to exercise judgment on behalf of others (people, institutions, etc.) and also has interests or obligations of the sort that might interfere with the exercise of her judgment, and which the person is morally required to either avoid or openly acknowledge.

A broker owes a duty of loyalty to its client and a duty of care to its markets. While the fiduciary and relational obligations clearly lie in representing the clients' interests first and best, this in no way abrogates the responsibility for full and proper disclosure of all information that would impact an underwriter's acceptance and pricing of a risk.

The conflict currently facing brokers is the long-standing debate, and now litigation (not a subject of this paper), concerning "contingent commissions", that is, fees paid to brokers by underwriters based usually on the metric of total business volume provided. Clients and regulators will express genuine concern that volume targets and the economic rewards that go with meeting them will motivate a menu of ethically unacceptable behaviors on the part of the broker:

- A reduction in options, as only those markets agreeing to the contingency payments will be given the opportunity to bid on an account;

- A structure that promotes "bid-rigging", that is, simply creating the appearance of alternatives having been sought for the client by "assigning" competitive and noncompetitive quotations to different insurance carriers;

- A conflicted sense of advocacy obligations; on behalf of a small client with a disputed claim, will a broker really be willing to push an underwriter whose contingency payments represent millions of dollars to the firm?

- Internal reward systems at the broker's which run counter to the interest of the client, that is, rewarding a profit and loss centre on its growth in contingency commissions, and not on a more client-centric metric.

Brokers have long argued, and often with plausible data to support them, that the quality control function in the massive paper flows associated with issuing insurance products has essentially been outsourced to them by insurance companies, and without due compensation (other than contingency commissions). Conservative estimates put the error rate in issued insurance policies at no less than 30-40 per cent. Further, for anyone operating in a financial services industry, one of the largest costs in the system

\footnotetext{
${ }^{9}$ Author's note: As this article was being completed, the New York Attorney General's office announced a series of actions being taken to challenge the legality of contingency, or volume commission arrangements, between brokers and underwriters. It is not the intent of this article to address the legal issues involved in any manner, nor has the author attempted to provide other than a balanced view of the ethical issues raised.
} 
will always be the expense associated with unsuccessful sales efforts. As they act as the distribution system for the industry, brokers have a case to make that contingency payments are a legitimate means for others in the chain of commerce to share this cost.

As the data systems at insurance companies are generally unable to assign a contingency commission value to any given account, brokers will also argue that there is no client-specific metric that motivates a potential conflict. Finally, and in the insurance industry it is an argument that often carries some weight, "... it is the way we have always done it." Contingency commission arrangements have been a pervasive industry practice, long enjoyed by brokers, and in fact often promoted by underwriters. Perhaps most importantly, it is an industry practice no large corporate client could claim ignorance of. Does that constitute tacit approval?

The issue has gained the notoriety that it has because, for the global brokers, contingency/volume payments from underwriters became a number large enough to be noticed, and because process management at many firms has driven them to become more effective at leveraging larger contingency payments. The current investigations have at their core legitimate questions concerning "bid-rigging" and manipulation of quotations, thus eliminating the sort of honest auction brokers are meant to conduct as the means of assuring best terms possible for their clients. Scale and process remain the drivers in an industry that is changing.

Few would argue that volume payments to brokers by insurance companies represent an "alignment of interests" with respect to the buyers served by the broker. The critical point, often overlooked, is that the absence of an alignment of interests does not in and of itself constitute a conflict of interests. To make a case for ethical malfeasance, one would have to demonstrate that the existence of the contingency system actually changes the behavior of brokers at the account-specific level.

Brokers operating what might now best be termed a "traditional contingency" arrangement, that is, without a profit centre approach to the specific revenue stream, and free of the allegations of "rigging" (for which there is simply no defence) facing some, would cite the following as the reasons for their "no conflict" position:

- Evaluation and reward systems place a premium on client retention and new client production; there is no reward mechanism for a placing broker in meeting a metric (i.e., how much of a contingency did we get on this particular account) that simply can't be measured with any veracity.

- Particularly for the multinational clients that have in fact registered some of the loudest protests with respect to volume commission arrangements, the selection of carriers to approach on any given placement is typically a decision made with the active involvement of the client. Brokerage processes in place also require a client's $a$ priori "blessing" before any market is approached.

- Line underwriters making account-specific decisions with respect to the acceptance and pricing of risk are not involved in the negotiation of volume commissions with brokerage firms; like their placing broker counter-party, they often operate in the blind with respect to these arrangements.

- Competition cures all. A brokerage firm driven by undue interests in driving its volume commissions would place itself at a competitive disadvantage requiring an adjustment in strategy. 
All this being said, the perception issues will remain. As an intermediary, how can I be paid by both parties to the transaction(s) without my obligations to the client being impacted? The very legitimate response to this question cannot help but be perceived as already tainted by self-interest, and the fact remains that defending your pricing structures (not quantums) is rarely a winning proposition for the long term.

The uproar over contingency commissions is an unfortunate example of how legacy methodologies in the craft model of brokerage do not always translate well when simply "leveraged" by global brokers utilizing both scale and process. The insurance industry is one long populated by companies sometimes guilty of simply saying, "We are very good at what we do, now let's do it bigger."

What is well and truly needed is a ground up rebuilding of how global brokers construct their relationship with global clients and how they price their services. Coupled with continuing improvements in the management and development of the staff that constitutes their most important resource, they can create the operational structures and company cultures that allow scale and process to be deployed as assets mutually supportive of high ethical standards and not as hidden liabilities.

\section{Avoiding jellyfish syndrome: success as a global broker}

From the Australian Museum:

The Bluebottle or Portuguese Man-of-War is not a single animal but a colony of four kinds of highly modified individuals (polyps). The polyps are dependent on one another for survival. ${ }^{10}$

This colony, which to only an outsider appears to be a single organism moving with some purpose, is in fact simply adrift, has only survival as its goal, and ultimately would (if it could) have to view success or failure as simply a product of randomness arising from externalities such as the wind.

Our economic beaches have been littered over the past few years with primarily "jumbo" companies washing ashore as a direct result of management failing to grasp and then act on the fact that operational success is wholly dependent on the proper alignment of people, operational structures, processes, and the ethical context of the firm. Particularly in the field of insurance brokerage, doing the "right thing" is not just morally correct, it will in fact make you more money. This "proper alignment" will not result from simply "leveraging" and/or "tweaking" the craft model of brokerage.

For an industry whose critical asset is the intellectual capital of the firm, senior management at leading brokerage firms will increasingly come to recognize training as the critical tool for implementation of new strategies, new tactics. With respect to staff, continuous training, at all levels, must become viewed as the most important deliverable required of the firm in the employment compact. The training should

\footnotetext{
${ }^{10}$ Australian Museum Online (2004).
} 
include an ethics component in every real and/or virtual session, and thought should be given to utilizing new technologies that allow for "stress testing" lessons learned through scenarios/simulations.

The global brokerage firms should also worry much less about institutionalizing clients and much more about institutionalizing staff (then the client retention issue will take care of itself). This is of critical importance for companies managing through the change required to embrace a process management approach to brokerage; in a business that for years has attracted primarily a "high touch" personality for employees, there is real risk in conveying, however unintentionally, " ...you are now just part of the machine..." For every change initiative undertaken, a specific plan of action for dealing with the human element, those threatening by-products (conflict, confusion, created incompetency, loss) should be put in place.

Managing the cultural, operational, and ethical risks present in a major cross-border placement is in itself a full-time job. It is not enough to hang the prefix "global" on somebody's title; only those employees who have been carefully selected and trained should be engaged in the management of the international component of an account, and it should be the sole focus of what they do on a day to day basis. Just as our heads of states need a foreign minister, even the most able client executive would benefit from help in managing the complexities of a global account.

Paradoxical though it may sound, in brokerage firms moving towards greater specialization through both industry and risk segmentation, "generalists" become among the most valuable, and by definition, most rapidly declining asset. They are still needed for final assembly of the service packages, yet the current structures are less likely to produce the "craftsmen" that normal attrition will carry away. A specific plan of action to continuously replenish a cadre of senior staff, with experience in multiple disciplines, is required.

Global brokerages should be wary of consultants and be careful not to confuse pompous reductionism for profundity. There is no end to the "process solutions" that can be embedded in any organization of size. The real issue lies in whether in the aggregate the processes installed are in fact achievable by staff, comprehensible to clients, and actually productive of value for the firm.

Be open to lessons learned in other financial services industries, but be cautious about rushing to a solution implementation that has not been fully vetted in the light of the many peculiarities that surround the risk business.

Particularly with the Fortune 2000 global client segment, the relationship with the client would benefit from some reconstruction:

- Especially as regards manuscript forms, the client and the underwriter both should sign the contract of insurance (a practice long prevalent in many countries); brokers are simply not paid enough to be an unspoken party to a contract between two knowledgeable counter-parties, as occurs with a contract of adhesion.

- Recognizing that the size and strength of their balance sheets provides a "backstop" for clients, via E\&O suits, that smaller brokers do not offer, global brokers should either take this "value offering" off the table, or price for it. For example, "my fee is $\mathrm{X}$ if you agree to binding arbitration between us, it is $\mathrm{X}+$ if you wish to retain a right to litigate against us...." 
- Create pricing structures that better align interests and eliminate even the hint of conflict.

The economic structure of brokerage firms is such that the margin is, has been, and always will be in the transaction. Seeking to protect their transactional margins, brokerage firms began, years ago, adding additional services they rarely knew how to cost and clients rarely knew how to value. That what resulted is an industry with severe confusion surrounding the issue of pricing should surprise no one.

Global brokerage firms should consider moving to an asset-based fee, charging clients for their services in much the same manner as investment and/or pension fund managers. In this system, the fee charged would be a percentage, usually on a decremental scale, of the assets (e.g., total values for property insurance, total sales for product liability, etc.) "risk managed" on the client's behalf. Advantages would include the following:

- An absolute alignment of interests for the client; the broker is not penalized for the good performance that results in a lower premium, nor do they experience a windfall because time and circumstance happen to have produced a "hard market".

- A stable revenue base for the intermediary; there are capital market reasons why insurance companies will always be subject to a certain volatility in their revenues; no one benefits from this volatility being passed to the distribution component of the commerce chain.

- A more professional pricing structure, linked not to a sometimes capricious metric such as "premium", but instead to the underlying asset where value is being added, client and broker both should become more skilled at setting a value on the services provided.

Ideally, such a pricing structure would be put in place with a certain uniformity brokers have often resisted and allow for the eventual elimination or modification of the contingency/volume commission arrangements now in place with underwriters, and causing such consternation.

Finally, in setting the ethical context of a firm, no factor is of greater importance than the modelling, the leadership that comes from the top. While reams have been and will be written about the components and value of leadership in an organization, much less time has been spent on the issue of how that dynamic changes for companies in transition, for companies moving to a process-centric model for their business. George Patton understood the dynamics of leadership well and made an observation that we can all take to heart:

There is a great deal of talk about loyalty from the bottom to the top. Loyalty from the top down is even more necessary and much less prevalent. ${ }^{11}$

Each of the global brokerage firms has management teams in place, competently coping with the issues addressed in this paper, and many others, on a daily basis. They

${ }^{11}$ Axelrod (1999, p. 153). 
are engaged in continuing to build a new model for a dynamic component in our industry; it won't be without effort.

\section{References}

Australian Museum Online (2004) 'The Bluebottle or Portuguese Man-Of-War', from http://www.amonline.net.au/factsheets/bluebottle.htm, 27 Sept. 2004.

Axelrod, A. (1999) Patton on Leadership: Strategic Lessons for Corporate Warfare, New York: Prentice Hall.

Batchelor, C., Skorecki, A. and Simensen, I. (2004) 'Citigroup displays contrition and citigroup memo', Financial Times, 15 September 2004, p. 27.

Beauchamp, T.L. and Bowie, N.E. (eds.) (1988) Ethical Theory and Business, 3rd edn, Englewood Cliffs, New Jersey: Prentice-Hall.

Berreby, D. (2004) 'Are you a man of character?' Men's Health (October): 192-199.

Dizard, J. (2004) 'Finger points at the broker barons in their rent-collectors' castles', Financial Times, 18 October 2004, p. 16.

Huffington, A. (2003) Pigs at the Trough: How Corporate Greed and Political Corruption are Undermining America, New York: Crown Publishers.

Hughes, J. and Kelleher, E. (2004) 'Marsh to halt special deals with insurers', Financial Times, 16/17 October 2004, pp. 1, 8, 11, 16.

Kelleher, E. and Wighton, D. (2004) 'Brokers may have to return payments', Financial Times, 19 October 2004, pp. 1, 18, 21, 22.

Kelleher, E. (2004a) 'Rigged bids and cheated customers': Eliot Spitzer takes aim at the insurance industry', Financial Times, 29 October 2004, p. 11.

Kelleher, E. (2004b) 'Spitzer blasts 'corrupt' insurers', Financial Times 15 October 2004, pp. 1, 14, 21, 28.

Nietzsche, F. (1966) Beyond Good and Evil: Prelude to a Philosophy of the Future, Walter Kaufmann (tr.), New York: Vintage.

Politi, J. (2004) 'Eliot Spitzer goes after his biggest fish yet', Financial Times, 18 October 2004, p. 16.

Pollard, C.W. (2004) 'Mission as an organizing principle', Leader to Leader Institute, http://www.pfdf.org/ leaderbooks/121/spring2000/pollard.html, 28 September 2004.

Simensen, I. and Ibison, D. (2004) 'Citigroup apologizes for $15 \mathrm{~m}$ euro bond coup as Japanese arm faces penalties', Financial Times, 15 September 2004, p. 1.

Supreme Court of the State of New York, The People of the State of New York, by Eliot Spitzer, Attorney General of the State of New York, Plaintiff, against Marsh \& McLennan Companies, Inc. and Marsh, Inc., Defendants, Supreme Court of the State of New York County of New York.

The Midlands Management Companies (2004) Statement of Ethics from http://www.midlandsmgt.com/ ethics.asp, 28 Sept. 2004.

Thorpe, D., Patrino, P.F., Murray, A. and Barry, M.J. (2004) 'Commercial Property/Casualty Insurance: Impact of New York Attorney General's Probe', Fitch Ratings, http://www.fitchratings.com, 26 Sept. 2004.

Tobias, A. (2004) 'The Day They Couldn't Fill the Fortune 500', http://www.andrewtobias.com/columns/ 980303.html, 20 Sept. 2004.

Wighton, D. (2004) 'Shifting the focus: chuck prince sets new goals for the vast Citigroup empire', Financial Times, 6 October 2004, p. 15.

World's Largest Insurance Brokers: Ranked by 2003 Brokerage Revenues, Business Insurance 19 July 2004, p. 16.

\section{About the Author}

James W. Hutchin is the president and founder of Alba Advisors, LLC, a firm that provides clients with strategic consulting advice as respects insurance-related ventures, and the training of insurance professionals. Jim also serves as an Executive in Residence and Clinical Faculty, at the Fox Graduate School of Business, Temple University. 
372

Mr. Hutchin began his career in 1979 with a major U.S. insurance broker, where he held a number of key management positions overseas in Italy, Singapore and Mexico. He later went on to run the global business practice at two major insurance brokerage firms, and subsequently became CEO of a large captive management company.

Mr. Hutchin's undergraduate work was completed at Randolph-Macon College in Virginia, with a Bachelor of Arts in Philosophy and Asian studies. He earned a Masters of International Management, with honors, at the American Graduate School of International Management ("Thunderbird"), and also attended "The Executive Program" at the Darden Graduate School of Business, University of Virginia. His Chartered Property and Casualty Underwriter ("CPCU') designation was obtained in 1981, and he was a founding member of the Society of CPCU's International Section's Governing Committee. With a penchant for writing, he has had more than twenty articles/interviews appear in publications such as Risk Management, International Insurance Report, National Underwriter, Institutional Investor, The John Liner Review, Business Insurance, International Quarterly, The Geneva Papers on Risk and Insurance, Insurance Networking, CFO Europe, and others. 